\title{
HCV in Lymphoid Neoplasms
}

\author{
Tsutsumi $\mathrm{Y}^{*}$, Yamamoto $\mathrm{Y}^{2}$, Ito $\mathrm{S}^{1}$, Kikuchi $\mathrm{R}^{1}$, Matsuoka $\mathrm{S}^{1}$, Naruse $\mathrm{H}^{2}$ and Teshima $\mathrm{T}^{3}$ \\ ${ }^{1}$ Department of Hematology, Hakodate Municipal Hospital, Hakodate, Japan \\ ${ }^{2}$ Department of Gastroenterology, Hakodate Municipal Hospital, Hakodate, Japan \\ ${ }^{3}$ Department of Hematology, Hokkaido University Graduate School of Medicine, Sapporo, Japan
}

Author contributions: Ito S, Kikuchi R, Yamamoto Y, Matsuoka S, Naruse H, Teshima T has contributed equally to this report.

${ }^{*}$ Corresponding author: Tsutsumi Y, MD, PhD, Department of Hematology, Hakodate Municipal Hospital 1-10-1, Minato-cho, Hakodate 041-8680, Japan, Fax: +81-138-43-4426, Tel: +81-138-43-2000, E-mail: yutsutsu@shore.ocn.ne.jp

Citation: Tsutsumi Y, Yamamoto Y, Ito S, Kikuchi R, Matsuoka S, et al. (2016) HCV in Lymphoid Neoplasms. J Hematol Blood Disord 2(2): 202. doi: 10.15744/2455-7641.2.202

Received Date: April 18, 2016 Accepted Date: June 27, 2016 Published Date: June 29, 2016

\begin{abstract}
In some HBV carrier cases, there have been reports of HBV reactivation and liver damage occurring during rituximab combination chemotherapy. Recently, with regard to the use of rituximab combination chemotherapy to treat non-Hodgkin's lymphoma in people infected with HCV, it has been suggested that there may be a connection between HCV and the severity and frequency of liver damage. Although these studies have mainly been retrospective, it is still debatable as to whether liver damage increases or becomes more severe when using rituximab combination chemotherapy to treat non-Hodgkin's lymphoma with HCV infection. In these HCV infected nonHodgkin's lymphoma cases, the difference in prognosis compared with patients without HCV infection is also a key issue. On the other hand, it was recently reported that in some cases of B-cell non-Hodgkin's lymphoma, the use of interferon or a direct-acting antiviral agent against cases of HCV infection either reduced the lymphoma or brought about remission in combination with rituximab, which raises the possibility that treating $\mathrm{HCV}$ with antiviral therapy may be effective against lymphoma and may contribute to the vital prognosis. In this review, we present an outline of the current findings relating to non-Hodgkin's lymphoma with HCV infection based on these reports.
\end{abstract}

Keywords: Rituximab; Hepatitis C virus; Non-Hodgkin's lymphoma

List of Abbreviations: HCV: Hepatitis C virus; NHL: Non-Hodgkin's lymphoma

\section{Introduction}

$\mathrm{HCV}$ is one of the causative factors of liver cancer, which has an incidence 25-35 times higher in HCV positive patients compared to healthy individuals $[1,2]$. Furthermore, it has been reported that liver cancer can develop without cirrhosis in HCV positive patients. Thus, it is important to control HCV to prevent development of liver cancer. On the other hand, exactly how HCV is involved in causing liver cancer remains unclear [2]. It has been reported that HCV may also play a role in lymphoproliferative disease, although the correlation between the two is still unclear $[3,4]$, and its effects may be indirect. HBV reactivation has been reported during the treatment of malignant lymphoma and autoimmune disease with rituximab in patients who are HBV positive, and preventive measures against HBV reactivation are being developed [5,6]. With regard to cases of HCV infection, a sizeable review of cases of severe liver damage in chemotherapy and rituximab combination chemotherapy has been conducted [7]. It is debatable whether the liver damage was caused by reactivation of HCV or was facilitated by the HCV infection. It is of interest to determine whether HCV affects the treatment and prognosis of lymphoma [8,9]. In this review, these points are outlined based on previously published studies.

\section{Mechanism of HCV reactivation during rituximab treatment}

One proposed model for HCV reactivation is that during rituximab treatment, the HCV viral load increases due to a reduction in the number of $\mathrm{B}$ cells and a subsequent decrease in antibody production. However, the hypothesis that antibody production is reduced due to a reduction of $\mathrm{B}$ cells is not temporally consistent when considered alongside the time taken for HCV viral growth. In our study, although HCV-RNA increases after administering rituximab, and HCV continues to increase while rituximab is 
administered, when rituximab is not administered, it is claimed that HCV-RNA does not increase even when an anti-cancer agent is administered [10]. This may be because of problems caused by HCV proliferating by repeated replication due to the immunosuppressive effects of rituximab. Stamataki et al. reported that the rapid increase of HCV-RNA is not necessarily directly related to the proliferation of B cells themselves, but that the virus is carried to the liver due to HCV infection. They discovered that reinfection of the liver with $\mathrm{HCV}$ is likely to have an important bearing on in cases such as liver transplants, and that — according to in vitro studies - if HCV infected liver cells are incubated together with healthy peripheral B cells to cause antibody dependent cellular cytotoxity (ADCC), then the increase of HCV-RNA in the experimental group not using rituximab where the B cells are not destroyed is unchanged from the control group, but when ADCC is brought about by using rituximab, the B cells are destroyed and as a result the HCV-RNA increases compared with the control group [11,12]. These reports seem to explain the phenomenon whereby HCV-RNA increases rapidly after administering rituximab. However, it is difficult to explain the decline in HCV during treatment without rituximab, although the amount of virus initially increased in peripheral blood. Recovery of B cells following rituximab treatment takes at least 6-9 months and it is therefore unlikely that B cells are infected with HCV during this period $[13,14]$. It is possible that HCV replicates in peripheral blood and subsequently moves through the bloodstream to re-infect liver cells, where it is attacked by cytotoxic T cells (CTL) resulting in hepatitis [15]. However, basic studies on the mechanism of HCV reduction are lacking. Treatment with rituximab not only causes a decline in B-cells but also changes the balance of CD4 and CD8 $\mathrm{T}$ cells due to changes in the cytokine profile. HCV replicates more efficiently as the number of CD8 positive cells decreases, and once the cells recover, CD8 positive cells specific for HCV are then synthesized. After treatment with rituximab, the CD4/8 balance changes and the B cells decrease, resulting in immune suppression and proliferation of the HCV virus [16,17]. Furthermore, in the case of HCV infection, it is known that the virus cannot be eliminated even though HCV specific CTLs are produced [18,19]. It is speculated that upon HCV growth following rituximab treatment, the T-cells and B-cells are both affected, resulting in the production of escape mutants that evade HCV specific CTLs and establish immune tolerance against the host. This may promote chronic infection with HCV and prevent more severe hepatitis compared with HBV reactivation. However, it has been reported that liver damage in HCV-positive cases has no connection with the quantity of HCV virus so an increased quantity of HCV virus may not necessarily be needed, and it has been suggested that increased HCV virus, unlike HBV, may not be a factor behind liver damage occurring in chemotherapy when using rituximab in HCV-positive cases [9,20-22].

\section{Epidemiology of HCV reactivation during rituximab treatment}

Few large scale studies on HCV reactivation have been conducted and most studies were undertaken before rituximab was introduced as a treatment. Although a few sporadic reports on HCV reactivation and hepatitis exist, most are small in scale [9,10,23-26]. Several fatal cases due to hepatitis following HCV reactivation have been described in these reports [23,25]. Although the number of cases analyzed was small, Ennishi et al. reported a rate of hepatitis of $27 \%$ and $3 \%$ in HCV positive patients and HCV negative patients, respectively, along with a relatively high level of transaminase in HCV positive patients [26]. It was also reported by Arcaini et al. that $17.9 \%$ of patients who were HCV positive showed liver damage during R-CHOP (R: Rituximab, C: cyclophosphamide, H: hydroxyl doxorubicin, O: vincristine, and P: prednisone) treatment [9]. Together with the report by Ennishi, it appears that approximately $15-30 \%$ of HCV positive patients develop liver damage. Additionally, it was reported that progressive lymphoma was caused by fatal hepatitis and a delay in treatment due to liver damage [22]. On the other hand, a number of reports have indicated that it is not necessary to delay treatment despite the presence of liver damage, although more studies are necessary to confirm these results $[23,27,28]$. It has also been reported that reactivation of HCV is more frequently seen with HCV genotype II [29]. Therefore, HCV genotype may influence disease severity and reactivation rate. On the other hand, since the HCV viral load is not correlated with the severity of hepatitis requiring treatment as mentioned above, this means that the onset of severe hepatitis may be observed while hinting at the possibility of there being no correlation between the increased amount of virus after HCV treatment and the amount of liver damage after treatment. Further studies are necessary to confirm these observations [8,9,20-22].

\section{Relationship between HCV and non-Hodgkin's lymphoma}

HCV was reported to have a strong correlation with cryoglobulinemia [30-33]. However, cryoglobulinemia is rare in Japan, while non-Hodgkin lymphoma in HCV positive patients is more common. Therefore, this review will discuss HCV as a cause of B cell non-Hodgkin lymphoma.

Although several reports exist suggesting a correlation between HCV and B cell non-Hodgkin lymphoma [34-40], no conclusive evidence has been forthcoming. The incidence of lymphoma in HCV positive patients is approximately 0.5-25\% [7,8,41]. It also depends on the type of lymphoma. It was reported that marginal zone lymphoma (MZL), diffuse large B cell lymphoma (DLBCL) and lymphoplasmacytic lymphoma are strongly correlated with HCV [42]. Interestingly, there are reports of cases where HCV antiviral therapy has been used to achieve complete remission or partial remission, albeit with low-grade lymphomas [43-45]. Also, a variety of meta-analysis studies have found that at least $10 \%$ of non-Hodgkin's lymphoma cases are correlated with HCV in HCV endemic regions such as Italy and Japan [3,35,40,45-47], and Nieters et al. reported that people infected with HCV are more likely than healthy individuals to develop B-cell non-Hodgkin's lymphoma with a relative risk of 2-4 times [45]. Marcucci et al. summarized the possible mechanisms of HCV-induced lymphoma as follows: 1. Proliferation of lymphoma due to antigen stimulation; 2. Immune suppressive effect due to HCV infection; 3. Co-infection with an unidentified virus; 4 . Direct oncogenic 
role of HCV [48]. We first recognized the correlation between HCV and lymphoma upon encountering an HCV positive patient with DLBCL whose peripheral blood HCV-RNA rapidly increased before DLBCL recurrence [49]. Based on this observation, we stained lymphoma samples from HCV positive DLBCL patients using HCV-specific antibody. About $76.9 \%$ of samples were found to be HCV positive (either "strong positive" or "weakly positive"). However, this analysis found no significant correlation between the degree of HCV staining and the rate of recurrence or resistance to treatment [50]. Correlation between HCV and lymphoma was indicated epidemiologically as well as pathologically, as described in our study. HCV is nonetheless likely to play a role in B cell lymphoma; further evaluation of this hypothesis is needed.

\section{Prognosis of HCV positive lymphoma}

So far, the outcome of HCV positive malignant B-cell lymphoma and HCV negative B-cell lymphoma has only been addressed through retrospective analyses. Some have reported poor prognosis [27,41] while others reported good prognosis [28]; thus, no clear conclusions can be drawn on whether any difference in prognosis between these two types of lymphomas exist. In some cases, it was reported that younger patients with low-grade lymphoma were observed in the group with a favorable prognosis, whereas patients in the poor prognosis group had a tendency to have high LDH values. Thus, from currently available data, it is not possible to draw clear conclusions on prognosis since the disease status of patients in each group is varied and inconsistent [7]. Our previous study found a poorer prognosis in an HCV positive patient group; although the number of cases was small and statistical significance was not attained. Further studies and analyses are needed [7].

Merli et al. analyzed prognosis factors for 535 patients with HCV positive lymphoma who received anthracycline-based treatment and reported the following three prognosis factors: ECOG score of 2 or higher, albumin less than 3.5g/dl, and HCV-RNA load $>1,000 \mathrm{KIU} / \mathrm{ml}$. Using these factors, it is possible to categorize both OS and progression free survival (PFS) into 3 groups as follows: $0=$ low, $1=$ intermediate, $2=$ high risk [20]. Furthermore, it has been reported that treatment times are longer in cases of HCVpositive NHL combined with liver cirrhosis than in cases of HCV-negative NHL, which suggests the treatment is less effective and has an adverse effect on the prognosis [51,52]. Further studies by other groups are necessary to confirm this method.

\section{DAA treatment in HCV positive NHL patients}

The treatment of hepatitis $\mathrm{C}$ is currently changing: the conventional treatment with interferon is being replaced by a regimen of internal medication. In both the United States and Japan, it is recommended that treatment is performed by combining various DAAs according to the current HCV genotype [53-56]. In Japan, the HCV genotype is thought to be $70 \%$ genotype $1 \mathrm{~b}$, with genotypes $2 \mathrm{a}$ and $2 \mathrm{~b}$ being the next most common [19]. Treatment with a combination of DAAs is said to achieve a sustained virologic response (SVR) of roughly 75-95\%. Since therapeutic effects can be achieved without burdening the patient with inconveniences such as having to self-inject, the use of interferon is being dropped from the treatment of hepatitis C. Recent reports on the prognosis of patients with HCV positive lymphoma who received anti-viral treatment such as interferon showed better overall survival rate [50,57]. We also evaluated changes in HCV-RNA before and after treatment and found that patients whose HCV-RNA load decreased after treatment had fewer reactivation episodes than those with increased HCV-RNA after treatment [49]. Patients who received treatment for malignant lymphoma and became HCV negative with interferon treatment in particular showed no recurrence [50]. A report by Arcaini et al. reported that, at least in case of low-grade lymphoma, interferon treatment could extend OS [58]. This was the first report based on a clinical study, although the number of low-grade lymphoma cases was limited. Furthermore, according to recent reports, complete remission has been achieved using direct antiviral agents on low-grade lymphomas such as HCV-positive marginal zone lymphomas in combination with rituximab, which is very promising for the future [53,59-61]. Further studies on the effect of interferon post-lymphoma treatment on improvement of prognosis in patients with HCV-positive B cell lymphomas, including DLBCL, are awaited.

Based on this information, we designed an intervention trial where R-CHOP therapy was used to treat B-cell non-Hodgkin lymphoma with hepatitis $C$ (genotypes 1 and 2) as a complication, following which the hepatitis $C$ was treated with these antiviral medicines, and the patients are monitored for any improvement in the prognosis or reduction of recurrence. We started registration after gaining the approval of the ethics committee in June 2015. Although the number of patients is still small, there have been no cases of recurrence or death without additional treatment, such as rituximab, and we are awaiting the accumulation of results from further cases. We plan to conduct an interim analysis in the second year of the study. In the future, we expect that the combination of antiviral therapies will suppress the recurrence of malignant lymphoma, leading to a reduction in liver cancer and liver sclerosis.

\section{References}

1. Amin J, Dore GJ, O'Connell DL, Bartlett M, Tracey E, et al. (2006) Cancer incidence in people with hepatitis B or C infection: a large community-based linkage study. J Hepatol 45: 197-203.

2. Strauss R, Tomer A, Duberg AS, Hultcrantz R, Ekdahl K (2008) Hepatocellular carcinoma and other primary liver cancers in hepatitis C patients in Sweden-a low endemic country. J Viral Hepat 15: 531-7.

3. Matsuo K, Kusano A, Sugumar A, Nakamura S, Tajima K, et al. (2004) Effect of hepatitis C virus infection on the risk of non-Hodgkin's lymphoma: a metaanalysis of epidemiological studies. Cancer Science 95: 745-52.

4. Schöllkopf C, Smedby KE, Hjalgrim H, Rostgaard K, Panum I, et al. (2008) Hepatitis C infection and risk of malignant lymphoma. Int J Cancer 122: 1885-90. 
5. Tsutsumi Y, Yamamoto Y, Shimono J, Ohhigashi H, Teshima T (2013) Hepatitis B virus reactivation with rituximab-containing regimen. World J Hepatol 5: 612-20.

6. Liang R (2009) How I treat and monitor viral hepatitis B infection in patients receiving intensive immunosuppressive therapies or undergoing hematopoietic stem cell transplantation. Blood 113: 3147-53.

7. Cox MC, Aloe-Spiriti MA, Cavalieri E, Alma E, Gigante E, et al. (2012) HCV infection, B-cell non-Hodgkin's lymphoma and immunotherapy: evidence and open questions. World J Gastrointest Oncol 15: 46-53.

8. Yazici O, Sendur MA, Aksoy S (2014) Hepatitis C virus reactivation in cancer patients in the era of targeted therapies. World J Gastroenterol 20: 6716-24.

9. Ennishi D, Maeda Y, Niitsu N, Kojima M, Izutsu K, et al. (2010) Hepatic toxicity and prognosis in hepatitis C virus-infected patients with diffuse large B-cell lymphoma treated with rituximab-containing chemotherapy regimens: a Japanese multicenter analysis. Blood 116: 5119-25.

10. Tsutsumi Y Ichiki K, Shiratori S, Kawamura T, Tanaka J, et al. (2009) Changes in hepatits C virus antibody titer and viral RNA load in non-Hodgkin's lymphoma patients after rituximab chemotherapy. Int J Laboratory Hematol 31: 468-70.

11. Satamataki Z, Tilakaratne S, Adams DH, McKeating JA (2011) Rituximab treatment in hepatitis C infection: an in vitro model to study the impact of B cell depletion on virus infectivity. PLoS One 6: e25789.

12. Stamataki Z, Shannon-Lowe C, Shaw J, Mutimer D, Rickinson AB, et al. (2009) Hepatitis C virus associated with peripheral blood B lymphocytes potentiates viral infection of liver derived hepatoma cells. Blood 113: 585-93.

13. Reff ME, Carner K, Chambers KS, Chinn PC, Leonard JE, et al. (1994) Depletion of B cells in vivo by a chimeric mouse human monoclonal antibody to CD20. Blood 83: 435-45.

14. McLaughlin P, Grillo-López AJ, Link BK, Levy R, Czuczman MS, et al. (1998) Rituximab chimeric anti-CD20 monoclonal antibody therapy for relapsed indolent lymphoma: half of patients respond to a four-dose treatment program. J Clin Oncol 16: 2825-33.

15. Watanabe T, Tanaka Y (2013) Reactivation of hepatitis viruses following immunomodulating systemic chemotherapy. Hepatol Res 43: $113-21$.

16. Misumi I, Whitmire JK (2014) B cell depression curtails CD4+ T cell memory and reduces protection against disseminating virus infection. J Immunol 192: $1597-608$.

17. Melet J, Mulleman D, Goupille P, Ribourtout B, Waitier H, et al. (2013) Rituximab-induced T cell depletion in patients with rheumatoid arthritis: association with clinical response. Arthritis Rheum 65: 2783-90.

18. Chang KM, Rehermann B, McHutchisn JG, Pasquinelli C, Southwood S, et al. (1997) Immunological significance of cytotoxic T lymphocyte epitope variants in patients chronically infected by the hepatitis C virus. J Clin Invest 100: 2376-85.

19. Guglietta S, Garbuglia AR, Salichos L, Ruggeri L, Folgori A, et al. (2009) Impact of viral selected mutations on T cell mediated immunity in chronically evolving and self limiting acute HCV infection. Virology 386: 398-406.

20. Merli M, Visco C, Spina M, Luminari S, Ferretti VV, et al. (2014) Outcome prediction of diffuse large B-cell lymphomas associated with hepatitis C virus infection: a study on behalf of the Fondazione Italiana Linfomi. Hematologica 99: 489-96.

21. Ennishi D, Terui Y, Yokoyama M, Mishima Y, Takahashi S, et al. (2008) Monitoring serum hepatitis C virus (HCV) RNA in patients with HCV-infected CD20positive B-cell lymphoma undergoing rituximab combination chemotherapy. Am J Hematol 83: 59-62.

22. Visco C, Finotto S (2014) Hepatitis C virus and diffuse large B-cell lymphoma: Pathogenesis, behavior and treatment. World J Gastroenterol 20: 11054-61.

23. Pitini V, SturnioloG, Arrigo C, Leonardi S, Pino S, et al. (2010) HCV genotype 2 as a risk for reactivation in patients with B cell lymphoma undergoing rituximab combination chemotherapy: correspondence. Br J Haematol 150: 116-7.

24. Margnani M, Mangone M, Cox MC, Angeletti S, Veggia B, et al. (2011) HCV-positive status and hepatitis flares in patients with B-cell non-Hodgkin's lymphoma treated with rituximab-containing regimens. Dig Liver Dis 43: 139-42.

25. Dizdar O, Tapan U, Aksoy S, Harputluoglu H, Kilickap S, et al. (2008) Liver dysfunction after chemotherapy in lymphoma patients infected with hepatitis C. Eur J Haematol 80: 381-5.

26. Coppola N, Pisaturo M, Guastafierro S, Tonziello G, Sica A, et al. (2012) Increased hepatitis C viral load and reactivation of liver disease in HCV RNA-positive patients with onco-haematological disease undergoing chemotherapy. Dig Liver Dis 44: 49-54.

27. Arcaini L, Merli M, Passamonti F, Bruno R, Brusamolino E, et al. (2010) Impact of treatment-related liver toxicity on the outcome of HCV-positive nonHodgkin's lymphomas. Am J Hematol 85: 46-50.

28. Visco C, Arcaini L, Brusamolino E, Burcheri S, Ambrosetti A, et al. (2006) Distinctive natural history in hepatitis C virus positive diffuse large B cell lymphoma: analysis of 156 patients from northern Italy. Ann Oncol 17: 1434-40.

29. Sagnelli E, Pisaturo M, Sagnelli C, Coppola N (2012) Rituximab-based treatment, HCV replication, and hepatitis flares. Clin Develop Immunol doi: 10. $1155 / 2012 / 945950$.

30. Misiani R, Bellavita P, Fenili D, Borelli G, Marchesi D, et al. (1992) Hepatitis C virus infection in patients with essential mixed cryoglobulinemia. An Intern Med 117: 537-7.

31. Ferri C, Greco F, Longombardo G, Palla P, Moretti A (1991) Association between hepatitis C virus and mixed cryoglobulinemia. Clin Exp Rheumatol 9: 621-4.

32. Zignego AL, Ferri C, Giannini C, La Civita L, Careccia G, et al. (1997) Hepatitis C virus infection in mixed cryogloblinemia and B cell non-Hodgkin's lymphoma: evidence for a pathogenetic role. Arch Viol 142: 545-55.

33. Agnello V, chung RT, Kaplan LM (1992) A role for hepatitis C virus infection in type II cryoglobulinemia. N Engl J Med $327:$ 1490-5.

34. Zignego AL, Giannini C, Ferri C (2007) Hepatitis C virus-related lymphoproliferative disorders: An overview. World J Gastroenterol 13: $2467-78$.

35. Dai Maso L, Franceschi S (2006) Hepatitis C virus and risk of lymphoma and other lymphoid neoplasms: a meta-analysis of epidemiologic studies. Cancer Epidemiol Biomarkers Prev 15: 2078-85.

36. Ferri C, Caracciolo F, Zignego AL, La Civita L, Monti M, et al. (1994) Hepatitis C virus infection in patients with non-Hodgkin's lymphoma. Br J Haematol 88: 392-4.

37. Pozzato G, Mazzaro C, Crovatto M, Modolo ML, Ceselli S, et al. (1994) Low grade malignant lymphoma, hepatitis C virus infection, and mixed cryoglobulinemia. Blood 84: 3047-53.

38. Mele A, Pulsoni A, Bianco E, Musto P, Szklo A, et al. (2003) Hepatitis C virus and B-cell non-Hodgkin lymphomas: an Italian multicenter case-control study. Blood 102: 996-9. 
39. Duberg AS, Nordström M, Törner A, Reichard O, Strauss R, et al. (2005) Non-Hodgkin's lymphoma and other nonhepatic malignancies in Swedish patients with hepatitis C virus infection. Hepatology 41: 652-9.

40. Anderson LA, Pfeiffer R, Warren JL, Landgren O, Gadalla S, et al. (2008) Hematopoietic malignancies associated with viral and alcoholic hepatitis. Cancer Epidemiol Biomarkers Prev 17: 3069-75.

41. Besson C, Canioni D, Lepage E, Pol S, Morel P, et al. (2006) Characteristics and outcome of diffuse large B-cell lymphoma in hepatitis C virus-positive patients in LNH93 and LNH 98 Grope d'Etude des Lymphomes de l'adulte programs. J Clin Oncol 24: 953-60.

42. de Sanjose S, Benavente Y, Vajdic CM, Engels EA, Morton LM, et al. (2008) Hepatitis C and non-Hodgkin lymphoma among 4784 cases and 6269 controls from the International Lymphoma Epidemiology Consortium. Clin Gastroenterol Hepatol 6: 451-8.

43. Tasleem S, Sood GK (2015) Hepatitis associated B-cell non-Hodgkin lymphoma: clinical features and the role of antiviral therapy. J Clin Transl Hepatol 3: 134-9.

44. Pozzato G, Mazzaro C, Maso LD, Mauro E, Zorat F, et al. (2016) Hepatitis C virus and non-Hodgkin's lymphomas: meta-analysis of epidemiology data and therapy options. World J Hepatol 18: 107-16.

45. Nieters A, Kallinowski B, Brennan P, Ott M, Maynadie M, et al. (2006) Hepatitis C and Risk of Lymphoma: Results of the European Multicenter Case-Control Study EPILYMPH. Gastroenterology 131: 1879-86.

46. Gisbert JP, García-Buey L, Pajares JM, Moreno-Otero R (2003) Prevalence of hepatitis C virus infection in B-cell non-hodgkin’s lymphoma: systematic review and meta-analysis. Gastroenterology 125: 1723-32.

47. Negri E, Little D, Boiocchi M, La Vecchia C, Franceschi S (2004) B-cell non-Hodgkin's lymphoma and hepatitis C virus infection: a systemic review. Int J Cancer 111: $1-8$.

48. Marcucci F, Mele A (2011) Hepatitis viruses and non-Hodgkin lymphoma: epidemiology, mechanism of tumorigenesis, and therapeutic opportunities. Blood 117: $1792-8$.

49. Shiratori S, Tsutsumi Y, Kawamura T, Kudo K, Shimoyama N, et al. (2008) HCV non-Hodgkin lymphoma and transition of the serum HCV RNA level: a retorospective analysis in one institution. Int J Hematol 87: 298-302.

50. Tsutsumi Y, Ito S, Ogasawara R, Kudo K, Tanaka J, et al. (2011) HCV virus and lymphoid neoplasms. Adv Hematol doi: 10. 1155/2011/717951.

51. Mahale P, Kontoyiannis DP, Chemaly RF, Jiang Y, Hwang JP, et al. (2012) Acute exacerbation and reactivation of chronic hepatitis C virus infection in cancer patients. J Hepatol 57: 1177-85.

52. Vannata B, Arcaini L, Zucca E (2016) Hepatitis C virus-associated B cell non-Hodgkin's lymphomas: what do we know? Ther Adv Hematol 7: $94-107$.

53. Lok AS, Gardiner DF, Lawitz E, Martorell C, Everson GT, et al. (2012) Preliminary study of two antiviral agents for hepatitis C genotype 1. N Engl J Med 366: 216-24.

54. Kumada H, Suzuki F, Suzuki Y, Toyota J, Karino Y, et al. (2016) Randomized comparison of daclatasvir plus asunaprevir versus telaprevir plus peginterferon/ ribavirin in Japanese hepatitis C virus patients. Hepatology 31: 14-22.

55. Omata M, Nishiguchi S, Ueno Y, Mochizuki H, Izumi N, et al. (2014) Sofosbuvir plus ribavirin in Japanese patients with chronic genotype 2 HCV infection: open label, phase 3 trial. J Viral Hepat 21: 762-8.

56. AASLD/IDSA HCV Guidance Panel (2015) Hepatitis C Guidance: AASLD-IDSA recommendations for testing, managing, and treating adult infected with hepatitis $\mathrm{C}$ virus. Hepatology 62: 932-54.

57. Chung H, Ueda T, Kudo M (2010) Changing trends in hepatitis C infection over the past 50 years in Japan. Intervirology 53: $39-43$.

58. Arcaini L, Vallisa D, Rattotti S, Ferretti VV, Ferreri AJ, et al. (2014) Antiviral treatment in patients with indolent B-cell lymphomas associated with HCV infection: a study of the Fondazione Italiana Linfomi. Ann Oncol 25: 1404-10.

59. Arcaini L, Besson C, Peveling-Oberhag J, Loustaud-Ratti V, Rattotti S, et al. (2015) Anti lymphoma activity of interferon-free treatment in patients with indolent B-cell lymphomas associated with hepatitis C virus infection. Blood 126: 3938.

60. Sultanik P, Klotz C, Brault P, Pol S, Mallet V (2015) Regression of an HCV-associated disseminated marginal zone lymphoma under IFN-free antiviral treatment. Blood 125: 2246-7.

61. Carrier P, Jaccard A, Jacques J, Tabouret T, Debette-Gratien M, et al. (205) HCV associated B-cell non-Hodgkin lymphomas and new direct antiviral agents. Liver Int 35: 2222-7.

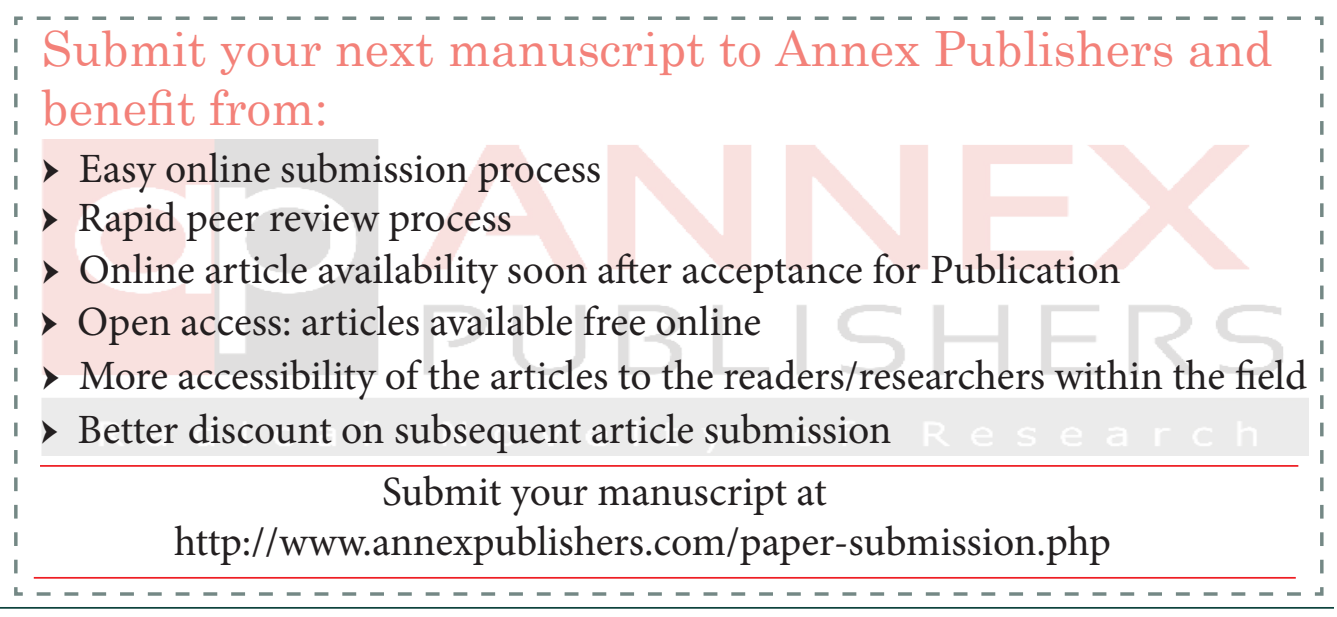

